\title{
STUDY SMART NOT HARD
}

\author{
Imane KAMSA \\ Faculty of Sciences \\ Moulay Ismail University \\ Meknes, Morocco \\ Dr. Rachid ELOUAHBI \\ Faculty of Sciences \\ Moulay Ismail University \\ Meknes, Morocco \\ Dr. Fatima EL KHOUKHI \\ Faculty of Arts and Humanities \\ Moulay Ismail University \\ Meknes, Morocco
}

\section{ABSTRACT}

Learners' concentration is an essential factor for learning and acquisition. The duration of concentration varies from one individual to another. Some learners have a long duration of concentration; whereas, others have a short one. Leaving the learner in front of a screen for a random duration is a strategy that does not optimize online learning. In this perspective, we have implemented an approach based on three intelligent agents customizing and adapting the learning time according to the learner's concentration time. The first agent is called "Detector Agent" (DA).The task of this agent is to measure the learner's concentration time and to detect the factors that may influence it. The second agent is named "Scheduler Agent" (SA). Its function is to cut the time of a session in proportion to the concentration time measured by DA and to program relaxing breaks in order to regenerate the degree of concentration. And finally, the third agent is called "Rectifier Agent" (RA). The latter is responsible for rectifying the factors that negatively influence the concentration of the learners. These agents continuously communicate between each other in order to ensure an efficient treatment. The experienced results show that the approach contributes effectively in the acquisition and the performance of learners. Success rates have risen sharply and the learners express a growing satisfaction.

Keywords: E-learning, concentration, intelligent agent, optimization, time planning.

\section{INTRODUCTION}

The concentration of the learner is an indispensable action for optimal learning (Dreidmy, 2012; Levasseur, 2012). It can be defined by the orientation of the set of mental activities of the learner towards a single learning object in a variable time period depending on each learner (Letarte \& Lafond, 1999). This action plays a fundamental role in the acquisition of knowledge. It facilitates comprehension, assimilation and memorization (Delsarte \& Nathalie, 2005). The concentration ensures maximum reception of all information whether they are visual or auditory (Ruph, 2010). This reception is supported by the learner's ability to mobilize his mental and physical faculties on a subject or action. The acquisition of new knowledge is directly related to the degree of concentration of learners (Goethe, 1832). It is the task that requires more concentration and effort. This effort is varied according to the requirements of the task and its duration. The more the 
task is complex, new and difficult, the more the effort to provide is large. The more time elongates, the more the effort to stay focused is important and sometimes impossible to arrive at a high degree of concentration if the duration is very long (Cosnerfroy, 2010; Ruph, 2011). In this perspective, it is important to support learner concentration to ensure maximum learning and effective intellectual work.

The concentration of the learner is strictly related to the notion of time (Hery, 2016). It is not sufficient or necessary to sit in front of a screen for a long period, to navigate in the distance learning system and to click on courses to have effective learning. We still need to put his brain running and to orient it on the task and this is not always easy. The synchronization between the learning time and the degree of concentration is a necessary step for an efficient acquisition (Lafond \& Letarte, 1999). In order to achieve this objective, a division of labor into small specific objectives corresponding to the learner's time of concentration is a positive step towards acquisition and learning.

The proposed approach in this paper, serves to accompany the learner in his learning process by putting on the right track to perfect his acquisition. This development is achieved by helping learners to determine their durations of concentration and cutting the learning into steps with pauses programmed between steps. The goal of relaxing breaks is to reactivate learners by helping them recover their high concentration levels for optimal acquisition (Mead, 2002). However, the concentration of the learner is variable and is not under the direct control of learners (Poissant, Falardeau \& Poellhuber, 1993). Several factors can influence it.

These factors can be classified into two categories (Balincourt, 2016):

$>$ Internal category: This category corresponds to the internal factors of the learners. They are numerous and difficult to detect for online learners where there is an absence of direct contact. These factors include: The motivation of the learner, emotional state, cognitive ability, physical fatigue and nervousness, personal problems, etc. The negative influence of these factors can cause the loss of the learner's time, which may be the source of his fatigue and discouragement.

$>$ External category: It represents the external factors associated with the external environment of the learners. We can cite as an example: the noisy environment of the learner, the adaptation of training, the quality of e-learning tools, etc.

The implication of these factors, whether internal or external, directly influences the concentration and attention of learners, which affects their learning.

The objective of this work was threefold:

$>$ Optimizing learners' acquisition by maximizing their concentrations through controls and refinements of the internal and external factors.

$>$ Automatically and dynamically estimating the learner online concentration time.

$>$ Personalizing the learning time according to the concentration of the learner by cutting the work to be performed in steps corresponding to the time of concentration of the learners and programing relaxing breaks between the steps.

These goals are achieved by integrating intelligent agents that act in an automated and dynamic way in the distance learning system. The first agent modeled in our approach is "Detector Agent" (DA) (Kamsa et al., 2017). This agent plays several roles to support the learner in learning process. Namely, the automatic estimation of learner concentration time and the dynamic adjustment of this time depending on factors that can influence them. The decision taken by DA is sent to the second agent "SchedulerAgent" (SA) (Kamsa et al., 2015). This agent has the role to cut the time envisaged at a learning session in short periods of time that are proportional to the time of concentration of the learner and integrate regenerative breaks of learner concentration between these short 
periods of time. And finally, the last agent modeled in the approach is "Rectifier Agent" (RA). This agent has the task of remedying the factors that negatively influence the concentration of the learners in order to optimize their learning.

\section{PROPOSED METHOD}

There is no lack of strategies for planning and managing learning time when it comes to classroom learning. The teacher takes the initiative to develop a set of tools to effectively manage the time of a learning session. Among these tools, we cite as an example: the plan of action which is a planning support of which the teacher foresees the chronology of the actions of learning, it does not signify a real progression (Musial, Pradere \& Tricot, 2012). The sequence scenario that also defines the process of conducting a pedagogical activity in student tasks (Musial, Pradere \& Tricot, 2012). The lesson plan or microplanning is also a short-term planning process. This tool is used by the teacher to model the progress of a learning session (Sorel-Tracy, 2013). These tools are carried out in most cases by the teacher. This shows the important role the teacher plays in helping learners sequence learning time so as to optimize memorization and understanding. However, in e-learning, having an available teacher planning in a personal and adapted way the learning time of each learner is a delicate and very expensive task. To this end, we have implemented an innovative input approach based on the multi-agent system. The choice of this intelligent technique proves to be very judicious and well suited to the characteristics of the target problem. This technique is very advantageous compared to other methods of learning time management and optimization (Boudjenah, Bruyas \& Aurin, 2016).

In this context, we can consider seven major advantages derived from a wide range of attributes:

$>$ Intelligent agents could replace man (tutor) so they could perform physical, social and cognitive actions.

$>$ Intelligent agents present no physical constraint (fatigue, occupation, rest, etc.). They are reactive.

$>$ Intelligent agents guide resolution to the most likely solutions.

$>$ Intelligent agents are fast and efficient entities that manage and maintain the work environment.

$>$ Intelligent agents save computing time and optimize processing via distributed resolutions.

$>$ Intelligent agents continuously provide channels for communication and collaboration between them.

Combined between this intelligence and the division of learning time according to the concentration of the learner will ensure an efficient acquisition and assimilation.

The Concentration is the basis of all learning. It is therefore extremely important to acquire the knowledge. To this end, we have developed an approach to improve the learning environment by adapting the learning tasks to the times when the learner's concentration is high. The aim of this approach is to lead learners towards optimal learning in a dynamic and intelligent way (Kamsa et al, 2016). This leading is achieved by regenerating the concentration of the learners by setting up relaxing breaks between the spots cut as a function of the concentration time. The following figure provides a brief description of our approach and the agents that they encompass. 


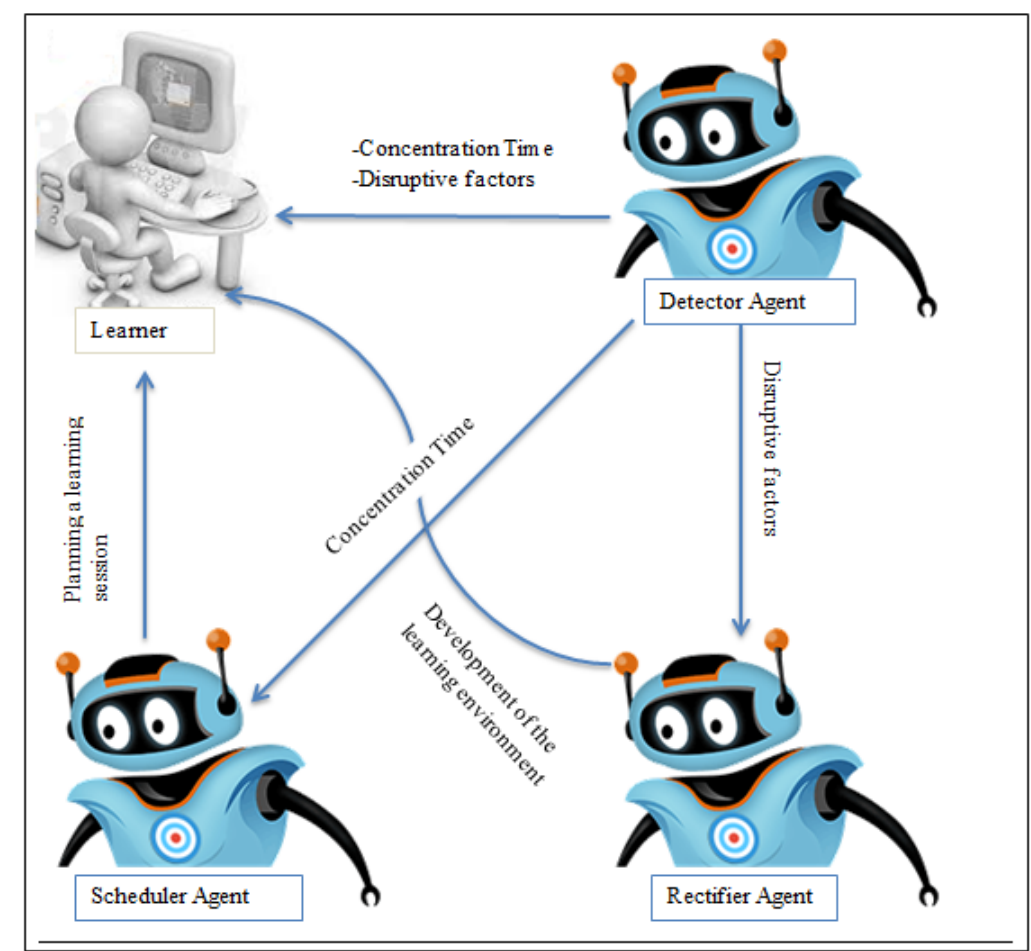

Figure 1. Multi-agent approach for optimal learning adapted to learners' concentration time

The following figure provides a simplified view of the functionalities encompassed in the proposed approach. The latter aims to optimize the learning of learners through intelligent agents which work dynamically in order to lead learners to taking courses at times when their concentrations are high. This method allows guaranteeing an acquisition and memorization optimal.

The process of treatment of each agent is described in the following section.

\section{Detector Agent DA}

Our primary objective was to be able to better satisfy learners in a distant learning system. To this end, it is necessary to establish communication channels continuously maintained therewith during the whole period of the connection and use of the system. This necessity arises mainly from the fact that on the one hand it should be able to estimate the learners' time of concentration so that it can divide the learning session into proportion according to this time. On the otherhand it could recover the factors that influenced them. In this perspective; an establishment of the detector agent is favorable.

This agent is a software representation accompanying users of the system (Ferber, 1999). The following figure describes the process operation of DA. 


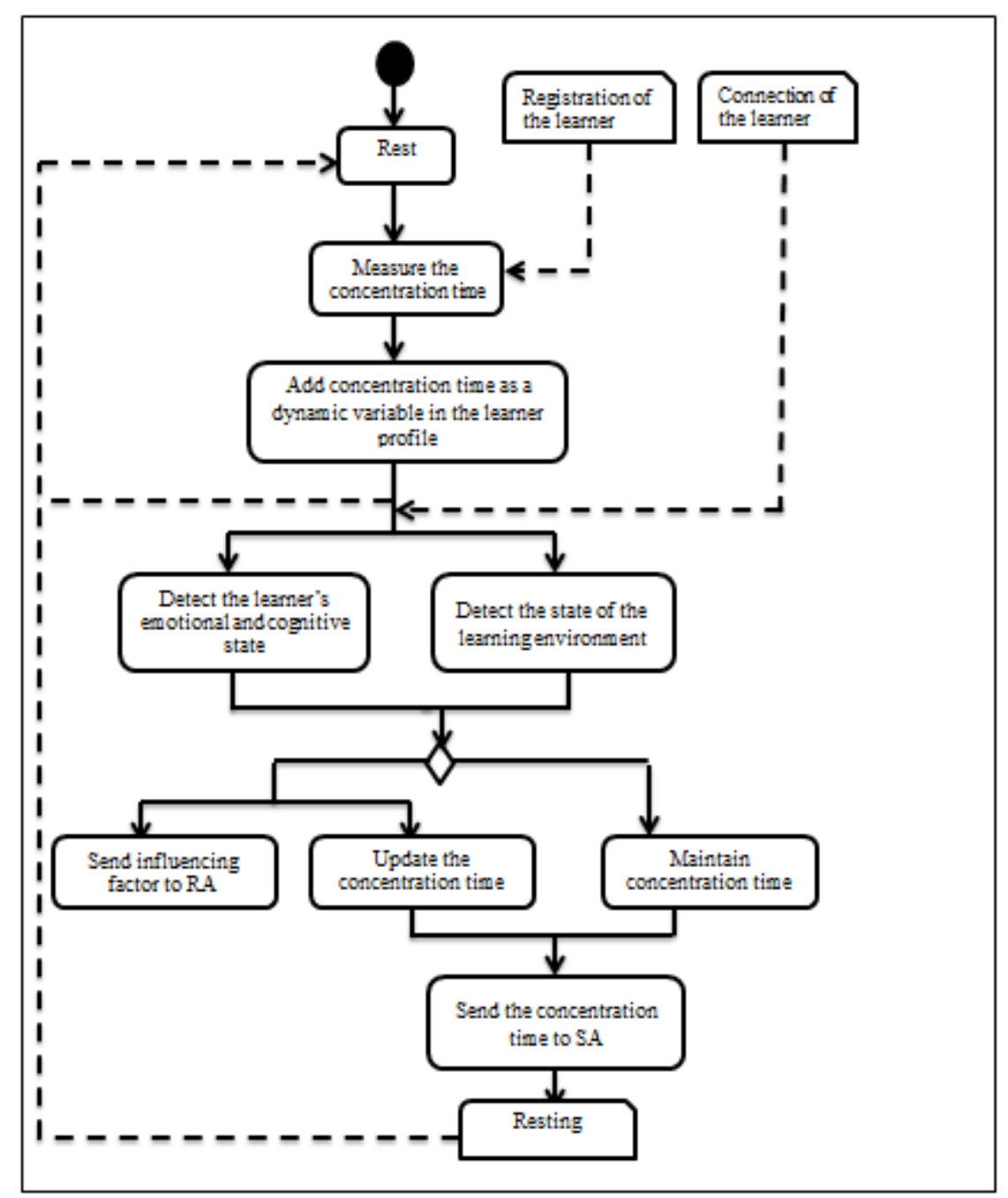

Figure 2. Activity Diagram of DA

Once the registration of learners is performed, DA seeks to determine their concentration time. This time will be recorded in the learner's profile as a dynamic variable. At each connection, the detector agent will enter into an interaction with the learner in order to be able to determine the cognitive and emotional state of the learner and also the state of the environment that surrounds him. This interaction is essentially based on sending to the learner a set of emoticons. The choice made by the learner allow DA to detect the emotional and physical state of the learner and also the state of the learning environment This helps the detector agent to know if there are influences on the concentration time. If the answer is yes, an update of concentration time is required. This update is determined according to the degree of influence of internal and/or external factors.

The calculated concentration time is sent by DA to SA in order to allow scheduling the learning session. The detector agent is also responsible for transmitting the detected influences to RA in order to rectify them.

\section{Calculate the Concentration Time}

Before defining how the detector agent calculates the concentration time of the learners, a definition of concentration should be given first.

\section{Definition of concentration}

Concentration is a mechanism that requires a considerable effort and a great willingness. We will understand why it does not last very long even though it is a long-term process, because it causes mental and physical fatigue ("Does intense intellectual activity 
consume more calories?", 2012). It is not a passive state, but a discipline of the spirit which requires to be developed, worked and trained.

\section{Measuring concentration}

As it is known, there is no test that accurately measures the concentration (Hodouin, 2016; Houst, 1997; Lamontne, 2014; Verner, 215). In most cases, it is done intuitively by the teachers through observation of behaviors and reactions of their learners. In the distance training system, our detector agent will do it automatically and also in an intuitive way via a set of criteria allowing to estimate the concentration time of each learner. The first criterion used by DA is the age of the learner. It is well known that concentration is a variable that depends on the age of the learner. For older learners, the duration of their concentration is prolonged according to their ages, given the consecutive work of the executive behavior of thought and attention (Sablonniere, 2016; ("The contributions of cognitive psychology", n.d.). On the other hand, concerning older learners, the quality and frequency of their concentrations decline with their ages. The older one gets, the more difficult it is to avoid being distracted when performing a mental activity requiring concentration (Christopher, 2014). This decrease is caused by the great difficulty in activating areas of the brain useful in activities requiring concentration ("A new study explains why age harms concentration", 2008). DA also takes into account the state of the learner and the environment of learning as a primary criterion of the concentration time calculation. A happy and motivated learner who is in a good physical condition and the environment of his learning is suitable surely ensures a high performance and concentration. In contrast, a learner who is sad, demotivated, tired and surrounded by noise will require a lot of effort and energy. The last information used by the detector agent is a constant agreed by a set of researchers who say that the average duration of the concentration of a learner can be twenty minutes without pause (Longour, 2014).

The formula used by DA to measure the concentration time is as follows:

$$
\begin{gathered}
\text { Concentration }_{\text {time }}=\left\{\begin{array}{c}
20+\frac{20+\text { age. }}{200} \text { if age }<60 \\
20-\frac{20+\text { age }}{200 .(F+1)} \text { if age } \geq 60
\end{array}\right. \\
{\text { With } \mathrm{F}=\text { Emotional }_{\text {state }}+\text { Physical }}_{\text {state }}+\text { Quality }
\end{gathered}
$$

\section{Scheduler Agent SA}

For each learner, who logs on and follows the learning process, a scheduler agent is created. This agent takes responsibility to cut the time of the session according to the concentration time of the learner and planning breaks of $5 \mathrm{~min}$ so that the concentration may remain optimal (Roulos, 2010). The breaks programmed by SA are not confined only to tell the learner that it is the time of breaks but also propose to this learner relaxing activities which contribute to the support of the concentration.

\section{Activities of Breaks}

Music

During the break, SA can propose to the learner to listen to musical tracks integrated in the platform of the distance training. These tracks allow creating calm, relaxing and regenerating environments (Lecourt, 2005). This regeneration allows the learner to assimilate the course during the next learning phase. 


\section{Spot Educational Actress}

The Scheduler agent can also propose to the learner in his break to watch an educative comedian spot considering the beneficial effects of laughter to counter the adverse consequences of stress (Frisch-Gauthier, 1961). A period of laughter can give the learner the pleasure of working and the urge to learn. This positive influence ensures a high concentration in the following learning phases.

\section{Food}

A good diet has a major role in the development of concentration (Barthes, 1961). In order to help the learner to keep a sufficient amount of calorie and energy, the scheduler agent gives a pause time sufficient to enable the learner to go in search of food and return to complete the process of learning.

These activities help learners to have a high degree of concentration considering the contributions they make to their physical and psychological condition.

\section{Rectifier Agent RA}

The rectifier agent is a more or less autonomous entity whose true functioning depends on the perceptions provided by the detector agent. The following figure describes the operation of RA.

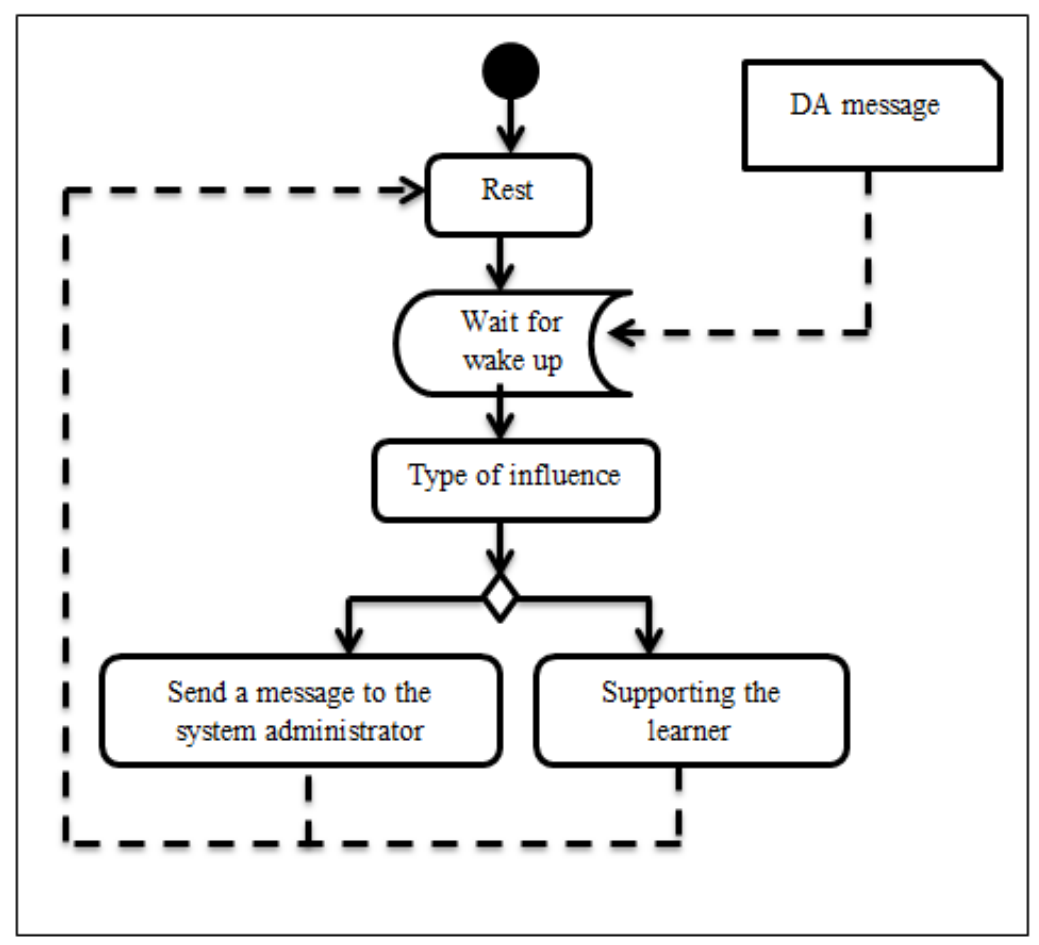

Figure 3Activity Diagram of RA

RA is put at rest pending a message indicating that the learner has suffered a negative influence during the learning process. This message also indicates the type of this influence. And according to this type, the rectifying agent determines its interaction.

There are two cases of RA interaction:

$>$ The first case is triggered when DA has detected an influence from the distance training system. For example, the course is inadequate; it does not meet the requirements of the learner. A lack of resources to master the course or content is unattractive. In this case, RA transmitted a message to the system administrator asking it to create attractive content, meet the needs of each learner and refine the system for the next sections of learning. 
$>$ The second case is triggered when the influence is internal coming from the learner. In this case, RA is responsible to assist the learner and remedy his internal state that affects his learning. Firstly, RA asks the learner to be interested in his learning environment through having a calm and favorable atmosphere. This atmosphere will surely put the learner in an optimal reception state. Then the rectifying agent is responsible for creating a rich emotional environment with the learner. It continually sends messages warmly welcoming the learners, in order to motivate and attract them to concentrate on their learning. RA also explains to learners that to succeed in studies, they must isolate the spirit of the outside world and extend in learning. And finally, the rectifier agent confirms to the learners that the error is part of the learning process and it is not bad. On the contrary, it ensures the acquisition and the memorization of the notions.

\section{TEST AND SIMULATION}

In experimenting our approach, we first want to demonstrate the existence of a strong dependence between the learners' concentration time and their percentages of acquisition. For this purpose, we have programmed evaluation tests for courses of the Computer Module for a sample of $\mathbf{5 0}$ students enrolled in the History course at the Faculty of Arts and Humanities, Moulay Ismail University, Meknes Morocco. These tests allow to measure the acquisition of this sample after the follow-up of the online courses. The programmed tests will be offered to learners in two different cases. The first case corresponds to a random condition i.e. a random concentration. The learners follow the course during a period chosen randomly. In the second case, the learners follow the course with a personalized schedule adapted to each learner. This schedule is created by the shoulder agent in which relaxing breaks are included. The results of this first experiment are analyzed by the SPSS statistical software. This method will allow us to determine whether there is a dependence between the learners' concentration time and their acquisition and whether this dependence is very significant. Also the experimentation will allow us to judge the usefulness of our approach and to determine the positive influence of the adaptation of the time of concentration on the acquisition of the learners and consequently on their successes.

Table 1. Measures the implication of concentration time in the success of the learner.

\begin{tabular}{lrrrrr}
\hline & \multicolumn{4}{c}{ Time of concentration * Level of success Crosstabulation } \\
\cline { 3 - 5 } & & \multicolumn{3}{c}{ Level of success } & \multirow{2}{*}{ Total } \\
\cline { 2 - 5 } & good mark & average mark & bad mark & \\
\hline \multirow{3}{*}{ Time of concentration } & calculated & 33 & 13 & 4 & 50 \\
\cline { 2 - 6 } Total & random & 9 & 18 & 23 & 50 \\
\hline
\end{tabular}

In this table (Table 1), we note that the proportion of learners who have a good and average mark in the test after the follow-up of the course during a period chosen by the system in a random manner was twenty-seven learners (54\%). While the proportion of learners who have passed the test after the follow-up during the intervals of time corresponds to their concentration was forty-six (92\%).

The difference between these two proportions (38\%) is very significant and proves the dependence between these two variables (concentration time and success of the learners). 
The results of this test also showed the positive influence of the planning of the time of a learning session according to the concentration time of the learners. A notable increase in the second test results after planning by SA compared to the first (Random).

These results prove the major role of the concentration of learners in their success. They also demonstrate the strong influence of the division of learning time according to the concentration time and the automatic programming of pauses.

We also proposed to the learners a questionnaire after the intervention of the rectifier agent. This questionnaire will allow us to measure our learners' satisfaction after RA support (Figure 4).

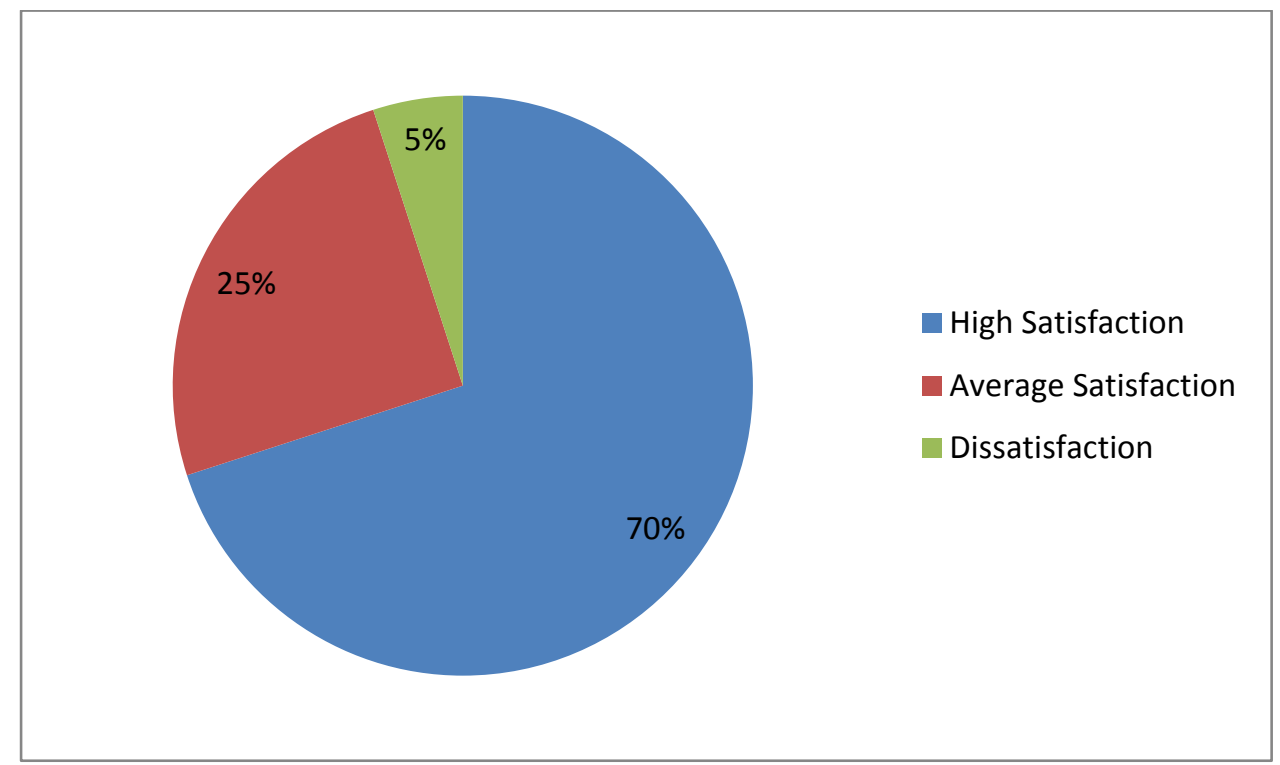

Figure 4. The learners' satisfaction after RA support

As shown in this figure, the majority of the learners $(70 \%)$ have expressed their high satisfaction after the support of the rectifier agent. They are very motivated and encouraged to follow their learning programs. While just $(25 \%)$ have revealed their Average satisfactions about the RA operation. And (5\%) reported their dissatisfaction after RA intervention and there is no influence on their returns and motivations. The conclusion that can be drawn from these results is that AR has played an important role in the support and accompaniment of learners.

\section{CONCLUSION}

Concentration is a very important cognitive state for learning. It participates extensively in the acquisition and memorization of courses. In this perspective, we have implemented an approach that helps learners to optimize their learning through intelligent agents. The main inputs of these agents reside essentially in the measurement of learner concentration time, automatic and personalized planning of learning time and rectification of the factors that influence learner concentration. These inputs contribute effectively to the acquisition and success of learners. The results of the experimentation are very encouraging and show the performance of the proposed approach. However, we want to improve our approach by proposing activities to make better and prolong learner concentration time. 


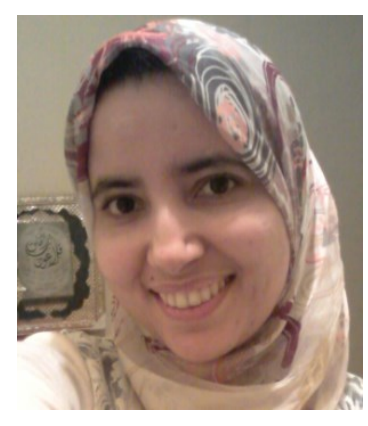

Imane KAMSA is a PhD student of Computer Sciences at Moulay Ismail University, Meknes Morocco. She earned a Master's degree in Computer Sciences in 2013. She also works as a temporary professor in the Faculty of Arts and Humanities, Meknes Morocco. Imane KAMSA is member of Computer Science and Applications Laboratory in the Faculty of Sciences of Meknes. Her research focuses on optimizing the learning path in distance learning, personalizing of online learning and performance of learners' acquisitions. She has published numerous articles and communications in these areas.

Imane KAMSA

Department of Mathematics and Computer Science, Faculty of Sciences

Moulay Ismail University, 50000, Meknes, Morocco

Phone: +21267507663

E-mail: i.kamsa@edu.umi.ac.ma

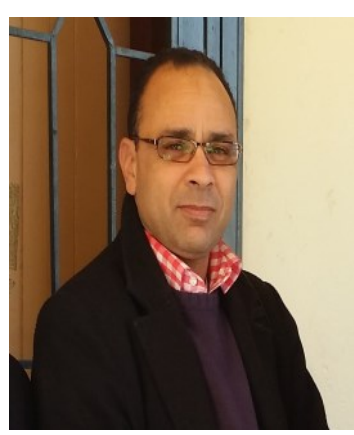

Dr. Rachid ELOUAHBI

Department of Mathematics and Computer Science, Faculty of Sciences

Moulay Ismail University, 50000, Meknes, Morocco

Phone: +21263349577

E-mail: elouahbi@yahoo.fr

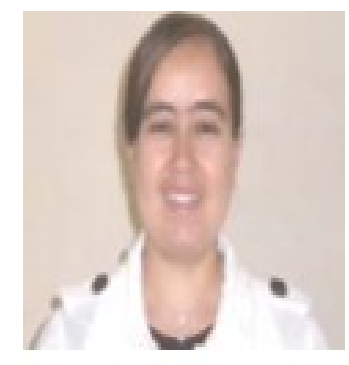

Fatima EL KHOUKHI is a Professor of Computer Sciences at Moulay Ismail University, Meknes Morocco. She is a member of the Modelling Applied Informatics in Humanities team at the Faculty of Humanities of Meknes, Morocco and a member of Operational Research and Computer team at the Faculty of Sciences and Techniques of Fez, Morocco. Fatima EL KHOUKHI works on scheduling problems and metaheuristics. She has numerous works in these areas. She is also a director of many doctoral theses.

Dr. Fatima EL KHOUKHI

Faculty of Arts and Humanities

Moulay Ismail University, 50000, Meknes, Morocco

Phone: $\mathbf{+ 2 1 2 5 8 7 4 2 2 7 6}$

E-mail: el_khoukhi_fatima@yahoo.fr 


\section{REFERENCES}

Balincourt, L. (2013). Concentration et adolescence : cherchez l'erreur ? [Concentration and adolescence: look for error?]. Le blog de developpement personnel pour les jeunes. Retrieved from http://www.parcoursduloupblanc.com/blog/ concentration-chez-les-adolescents-comment-les-aider/

Barthes, R. (1961). Pour une psycho-sociologie de l'alimentation contemporaine [For a psycho-sociology of the contemporary diet]. In Annales, economies, societes, civilisations. Persee-Portail des revues scientifiques en SHS, 16(5), 977-986.

Beggas, M. (2005). Modelisation par un systeme multi-agents d'un hypermedia educatif adaptatif [Modeling by a multi-agent system of an adaptive educational hypermedia]. Magister Informatique, Centre universitaire d'Eloeud.

Boudjenah, A., Bruyas. A \& Aurin, A. (2016). Comment I'intelligence artificielle s'est-elle developpee et jusqu'ou' va-t-elle progresser [How has artificial intelligence developed and how far will it go]. Retrieved from http://www.tpeia.sitew.fr/ Avantages Inconvenients. B.htm\#Definition et contexte.A

Christopher, R. (2014). L'attention [The attention]. Happy neuron Pro. Retrieved from http://www.scientificbraintrainingpro.fr/fonctions-cognitives/attention

Cosnefroy, L. (2011). L'Apprentissage autoregule: entre cognition et motivation [Selfregulated learning: between cognition and motivation]. Presses universitaires de Grenoble, 133-135.

Delsarte \& Nathalie. (2005). Stimulez votre memoire : memoire et concentration [Stimulate your memory: memory and concentration]. Online course, 1-9. Retrieved From http://www.eduvs.ch/lcp/methode/index.php?option $=$ com_content\&task =view\&id =6\&Itemid =5\&limit=1\&limitstart $=6$

Dreidemy, M. (2012). Concentration methode educative 3c et reussite scolaire [Concentration educational method 3c and school success]. Beroard Suzie, 1-51. Retrieved from http://www.methode3c.com/documents/Reussite-Scolaire--SUzie-BEROARD.pdf

Fab, V. (n.d.). Comment maintenir votre concentration à l'entrainement ou en competitions? [How to maintain your concentration in training or competitions?]. Retrieved from https://www.superhumains.com/concentration-entrainementcompetition/

Ferber, J. (1999). Multi-agent systems; an introduction to distributed artificial intelligence, Reading: Addison-Wesley, 1.

Frisch-Gauthier, J. (1961). Le rire dans les relations de travail [Laughter in labor relations]. Revue francaise de sociologie, 292-303.

Goethe. (1832). Comment mieux memoriser. Guide de reflexion sur les strategies d'apprentissage à I'universite [How to better memorize. A Guide to reflecting on learning strategies at the university]. Universite du Quebec en AbitibiTemiscamingue.

Hery, I. (2016). Concentration et attention en profondeur : duree moyenne et duree ideale [Concentration and attention in depth: average duration and ideal duration]. Retrieved from http: / / letempsreconquis.fr/concentration-et-attention-enprofondeur-duree-ideale/

Hodouin, M. (2016). Evaluer l'intelligence avec le QI, c'est depasse. Une equipe de profs à Yale a mis au point un outil de mesure de la concentration des etudiants [Evaluating intelligence with IQ is outdated. A team of teachers at Yale has developed a tool for measuring student concentration]. Slate-credit: info-sante.net. Retrieved from http:// www.meltycampus.fr/insolite-mieux-que-le-qi-le-quotient-deconcentration-des-etudiants-a477280.html 
Hourst, B. (1997). Au bon plaisir d'apprendre [At the pleasure of learning]. ed. Intereditions, Paris.

Kamsa, I., Elouahbi, R. \& El Khoukhi, F. (2017). Intelligent Agents for Dynamic Optimization of Learner Performances in an Online System. Journal of Information Technology Education: Research (JITE: Research), 16, 31-45 Retrieved from https://www.informingscience.org/Publications/3627.

Kamsa, I., Elghibari, F., Elouahbi, R., Chehbi, S. \& El Khoukhi, F. (2015). Learning time planning in a distance learning system using intelligent agents. In Information Technology Based Higher Education and Training (ITHET), 2015 International Conference on, IEEE, 1-4. Retrieved from http: / / ieeexplore.ieee.org/abstract/document/7218027/?reload=true

Kamsa, I., Elouahbi, R., El Khoukhi, F., Karite, T. \& Zouiten, H. (2016). Optimizing collaborative learning path by ant's optimization technique in e-learning system. In Information Technology Based Higher Education and Training (ITHET), 15th International Conference on, IEEE, 1-5. Retrieved from http:/ / ieeexplore.ieee.org/abstract/document/7760697/

L'activite intellectuelle intense consomme-t-elle plus de calories ? [Does intense intellectual activity consume more calories]. (2012) Retrieved from http://www.bodyscience.fr/ ?L-activite-intellectuelle-intense

Lamontagne, D. (2014). Deploiement, encodage : comment mesure-t-on I'attention [Deployment, encoding: how is attention measured]. Thot cursus, formation et culture numerique. Retrieved from http://cursus.edu/article/24330/deploiement-encodage-comment-mesureattention/\#.WMaN2m_JzIW

Lecourt, E. (2005). Decouvrir la musicotherapie [Discover music therapy]. Eyrolles.

Longour, M. (2014). Etudiants, musclez votre concentration pour travailler efficace [Students, muscle your concentration to work effectively]. Retrieved from http: / / www.reussirmavie.net/ Etudiants-musclez-votre-concentration-pourtravailler-efficace_a2094.html

Les apports de la psychologie cognitive [The contributions of cognitive psychology]. (n.d.). Retrieved from http://www.ac-grenoble.fr/ien.la-tour-dupin/IMG/pdf/Apport_de_la_psy_cognitive_de_la_chrono.pdf

Letarte, A. \& Lafond, F. (1999). La Concentration et la gestion du temps [Concentration and time management]. Centre d'orientation et de consultation psychologique de I'Universite Laval.

Levasseur, C. (2012). Methodes de travail efficaces [Effective working methods]. Hec Montreal, 1-15. Retrieved from http://www.hec.ca/etudiant_actuel/servicesofferts/ressources-pedagogiques/atelier_soutien_etudes/

Atelier.etude.efficace.pdf

Mead, P. (2002). Evolution des pauses dans l'apprentissage de l'interpretation consecutive [Evolution of pauses in the learning of consecutive interpretation]. These de doctorat, Universite lumiere Lyon 2.

Musial, M., Pradenf, F., \& Trlot, A. (2012). Comment concevoir un enseignement? [How to design a teaching?]. De Boeck.

Poissant, H., Falardeau, M. \& Poellhuber, B. (1993). L'attention en classe: fonctionnement et applications [Classroom attention: operation and applications]. McGill Journal of Education/Revue des sciences de l'education de McGill, vol. 28(2).

Roulois, P. (2010). Apprendre : connexions et repetitions [Learning: connections and repetitions]. Retrieved from https://neuropedagogie.com/bases-

neuropedagogie-neuroeducation/apprendre-connexion-et-repetition.html 
Ruph, F. (2010). Guide de reflexion sur les strategies d'apprentissage à l'universite (2e ed.) [A guide to reflecting on learning strategies at the university]. RouynNoranda, Quebec: Universite du Quebec en Abitibi-Temiscamingue.

Sablonniere, B. (2016). Les Nouveaux territoires du cerveau [The new territories of the brain]. Odile Jacob.

Sorel-Tracy, C. (2013). La planification d'une lecon[Planning a lesson].La presse pedago,2.

Une nouvelle etude explique pourquoi l'age nuit la concentration [A new study explains why age harms concentration]. (2008). Retrieved from http://www.lapresse.ca/sciences/medecine/200811/26/01-804426-unenouvelle-etude-explique-pourquoi-lage-nuit-a-la-concentration.php

Verner, R. (2015). Apres la mesure de l'intelligence, bientot le quotient de concentration? [After the measurement of intelligence, soon the quotient of concentration?]. Science \& Sante. Retrieved from http://www.slate.fr/story/110815/bientotquotient-concentration

Zenon d'Elee, G. (n.d.). Controler son attention et gerer sa concentration [Control your attention and manage your concentration]. Retrieved from http://web2.uqat.ca/profu/textes/strat_app/05concentration.htm 